\title{
Micaela Bastidas. Un fulgor que no cesa
}

\author{
SARA BEATRIz GUARDia
}

Micaela Bastidas Puyucahua nació el 23 de junio de 1744 en el pueblo de Pampamarca de la provincia de Tinta, Cusco. Huérfana de muy niña, su infancia, como la de sus hermanos Antonio y Pedro, fue de pobreza y restricciones. No aprendió a leer ni a escribir, y tampoco hablaba español, aunque sí lo comprendía. Pero ella, como dice el poema de César Calvo, “...dirige el rumbo de las grandes estrellas”.

José Gabriel Condorcanqui Túpac Amaru nació el 19 de marzo de 1741 en el pueblo de Surimana, distrito de Tungasuca, provincia de Canas, Cusco. Era el segundo hijo de Rosa Noguera y de Miguel Túpac Amaru, gobernador del pueblo de Surimana, descendiente de Manco Inca y bisnieto del inca Huayna Cápac, “Señores que fueron de estos reinos" (La rebelión de Túpac Amaru, 1971, vol. 2, p. 40). Al quedar huérfano, fueron el párroco de Pampamarca, Antonio López de Sosa, y el de Yanaoca, Carlos Rodríguez de Ávila, quienes le enseñaron a leer. A los 10 años ingresó a estudiar en el Colegio de Caciques de San Francisco de Borja, fundado en 1620 y dirigido por los jesuitas hasta su expulsión del Perú en 1767.

A la muerte de su hermano mayor, heredó el cacicazgo de los Túpac Amaru, cuyas tierras se extendían por los pueblos de Surimana, Pampamarca y Tungasuca. El 5 de octubre de 1766 inició los trámites para formalizar dicha posesión y viajó a Lima ( $\mathrm{La}$ rebelión de Túpac Amaru, 1971, vol. 2, p. 47). Entonces ya había iniciado una tenaz defensa de los indios contra el abuso de los españoles, a través de la aplicación de las Leyes de Indias y del cambio de las malas autoridades. Pero en Lima la relación con pensadores que posteriormente conformaron la Sociedad de Amantes del País fue decisiva en su formación política.

Según el acta de matrimonio (La rebelión de Túpac Amaru, 1971, vol. 2, p. 19), José Gabriel Condorcanqui Túpac Amaru y Micaela Bastidas se casaron en el pueblo de Surimana el 25 mayo de 1760. Él tenía 19 años, hijo legítimo de don Miguel Túpac Amaru y Rosa Noguera; mientras que Micaela, de 16 años, era hija natural de Manuel Bastidas y Josefa Puyucahua. El documento está firmado por el sacerdote Antonio López de Sosa, que permaneció con la pareja durante la insurrección. De esta unión nacieron tres hijos: Hipólito (1761), Mariano (1762) y Fernando (1768). 


\section{LA INSURRECCIÓN DE 1780}

El 4 de noviembre de 1780, José Gabriel Condorcanqui Túpac Amaru le tendió una emboscada al temido y odiado corregidor Antonio de Arriaga, apresó a sus colaboradores y el 9 de noviembre lo ejecutó. Poco después, decretó la supresión definitiva de la mita y del pago de impuestos. En el pueblo de Pomacanchi mandó abrir un importante obraje. Había empezado la más importante insurrección indígena de América Latina.

Durante las primeras semanas de noviembre, Túpac Amaru se aseguró la adhesión de varios pueblos aledaños llegando a contar, según el Informe del Cabildo del Cusco, con "un ejército de 60000 indios" (La rebelión de Túpac Amaru, 1971, vol. 1, p. 120). El 16 de noviembre promulgó el Bando de Libertad de los Esclavos y, dos días después, se produjo el primer enfrentamiento con el ejército español, que se rindió ante el avance impetuoso de las tropas rebeldes. El incendio de la iglesia sirvió de pretexto para que el obispo de Sangarará decretase la excomunión de Túpac Amaru, "por incendiario de capillas públicas [...] por rebelde traidor al Rey, por revoltoso y a todos cuantos le den auxilio, favor y fomento" (La rebelión de Túpac Amaru, 1971, vol. 2, p. 275).

Túpac Amaru avanza hacia el sur con el objetivo de extender la sublevación al Altiplano y al Alto Perú, y cortar la ruta de abastecimiento al Cusco. Lo recibieron triunfalmente en los pueblos de Canas, Acomayo, Canchis y Chumbivilcas. También en Puno y en los valles de Arequipa y Moquegua. Los primeros días de diciembre ingresó al Collao cruzando la cordillera de Vilcanota, mientras que su primo Diego Cristóbal Túpac Amaru avanzaba hacia las provincias situadas en la otra ribera del río Pilcomayo. En La Paz la conspiración estaba en marcha, en Oruro se organizaba un gobierno indocriollo y los hermanos Katari lideraban la insurrección en Chuquisaca.

Micaela Bastidas quedó al frente de la administración de Tungasuca, y es en este período, entre fines de noviembre y fines de diciembre, cuando su presencia empieza a perfilarse de manera definitiva. Cabría preguntarse por qué Túpac Amaru la eligió a ella, y no a uno de sus capitanes, para realizar tan difícil tarea. Porque conocía su fuerza, su lealtad, su amor. Es ella quien imparte las órdenes, otorga salvoconductos, lanza edictos, dispone expediciones para reclutar gente y envía cartas a los caciques:

Todos los guardias españoles e indios, y espías puestos por orden de mi marido Don José Gabriel Túpac Amaru, darán paso franco a los que con este pase fueren, sin hacerles el más leve perjuicio; pena al que contraviniere esta mi orden del castigo que corresponde. Tungasuca, noviembre 27 de 1780. Doña Micaela Bastidas. (Loayza, 1945, p. 9)

No vacila en dirigir cartas a los caciques con directivas claras, y de manera rotunda conmina a los gobernadores Núñez de la Torre y Matías Canal:

También doy a vuestras mercedes noticia que en breve pasará mi marido a la ciudad del Cusco, con la correspondiente guarnición; por lo que es necesario que la gente de 
vuestras mercedes esté alerta, para bajar luego que corra esta noticia; y si a esto no se avienen vuestras mercedes, prometo acabarlos de plano, como lo he ejecutado con los demás. Tungasuca, diciembre 7 de 1780. Doña Micaela Bastidas. (Loayza, 1945, p. 12)

En sus órdenes no existen sutilezas ni vacilaciones. Llama ladrones a los corregidores y apresa a quienes se niegan a obedecer a Túpac Amaru:

\begin{abstract}
Señores Gobernadores Don Baltasar Cárdenas, Don Tomás Enríquez y Don Mariano Flores. Ya habrá llegado la noticia a ustedes de cómo mi marido se halla actualmente, practicando precisas diligencias, a fin de librar este Reino de [...] los ladrones de los Corregidores, de que resultará un beneficio común a todo el Reino y nos veremos libres de semejantes abusos. Tungasuca, 15 diciembre de 1780. Doña Micaela Bastidas. (Loayza, 1945, pp. 13-14)
\end{abstract}

También le escriben a ella los más cercanos consejeros de Túpac Amaru: Diego Berdejo, Pedro Mamani, Melchor Castelo, Pedro Mendigure, Ramón Ponce, Antonio Bastidas, Andrés Castelo y Marcos de la Torre. También Tomasa Tito Condemayta, Ángela Pacuri, Francisca Herrera y Catalina de Salas y Pachacuti, así como los sacerdotes Pedro Juan de Luna, Domingo de Escalante, Carlos Rodríguez de Ávila y Gregorio de Yapes. Son cartas destinadas a informarle cuestiones puntuales y solicitudes de justicia, a través de las cuales se advierte que tenía autoridad suficiente para dirimir, juzgar y sentenciar. En ellas la llaman "muy señora mía", "muy amada hermanita mía”, "amantísima señora mía", "señora gobernadora".

\title{
CARTAS DE AMOR Y GUERRA
}

Pero es en las cartas que intercambiaron Micaela Bastidas y Túpac Amaru donde es posible seguir el curso de la insurrección, las acciones que emprendió, su carácter y el amor que le profesó. No obstante, es necesario tener en cuenta que estas cartas fueron dictadas por ella, pues no sabía leer ni escribir. Entre el 23 de noviembre de 1780 y el 23 de marzo de 1781, Micaela le envió 19 cartas. En ellas lo llama "Chepe”, "Chepe mío", “hijo Chepe mío”, “Chepe de mi corazón”, “hijo de mi corazón”, “amantísimo hijo de mi corazón”, y firma: “Tu Mica”, "tu amantísima compañera”, "tu amantísima esposa de corazón”. Del 27 de noviembre de 1780 a diciembre de ese año, Túpac Amaru le escribió 8 cartas. La llama "hija mía”, "hija Mica”, “hija”, y firma siempre “Tu Chepe”.

En su primera carta del 23 de noviembre de 1780, Micaela Bastidas le recomienda con afecto: "Te encargo que la comida que tomares sea de mano de los nuestros y de más confianza" (Loayza, 1945, p. 43). Al día siguiente le aconseja que para promover la lucha en Arequipa "es necesario enviar carteles para que se enteren de su contexto" (Loayza, 1945, p. 44).

Por su parte, en la primera carta de Túpac Amaru se advierte su preocupación: “Tener mucho cuidado con los que están en casa, y dile a nuestro Figueroa que no se 
descuide, con tener muy prontas las armas que estén allí. Altos de Livitaca, noviembre 26 de 1780" (Loayza, 1945, pp. 59-60). Juan Antonio de Figueroa, a quien Túpac Amaru llama afectuosamente "nuestro Figueroa", era un cercano colaborador del corregidor Arriaga que se alistó con los rebeldes, solicitando encargarse de los cañones; por eso en las batallas la eficacia de la artillería era nula. Según el obispo Moscoso, Figueroa “dirigía los tiros con ardid, para no dañar a los ejércitos reales” (Loayza, 1945, p. 61).

En las cartas que Túpac Amaru y Micaela Bastidas se escriben, la información y el mensaje son semejantes a los que se dirigen dos combatientes de igual rango. Son comunicaciones de guerra, con lo preciso y necesario; no existe mención que corresponda al ámbito privado, aunque Hipólito combatía con Túpac Amaru y Mariano cumplía varias tareas. El 27 de noviembre, Túpac Amaru le escribe desde Velille:

Acabo de recibir carta de Layo en la que me dan la noticia de que vienen soldados de Lampa y Azángaro; y así, precisa mucho que mandes poner toda la gente en el cerro de Chullocani hasta que yo regrese de este Velille, que será el viernes [...]. También será preciso que Don Juan Antonio Figueroa lleve todos los cañones a dicho cerro. (Loayza, 1945, p. 60)

El 2 de diciembre de 1780, Micaela le envía un reporte de las acciones: “En Carabaya se repiten muertes y embargos; de Caylloma se asegura la tranquilidad, y de Arequipa lo propio" (La rebelión de Túpac Amaru, 1971, vol. 2, p. 596). En su carta del 3 de diciembre, Túpac Amaru le informa que vienen soldados del Cusco:

por lo que te prevengo que te vengas con todos los soldados de casa hasta Langui, entonces puedes quedarte con Fernandito y Mariano, y los soldados que pasen con toda la gente a Langui y Layo; y así puedes estar en alguna parte segura [...]; no te olvides de los cañones, en todo caso que vengan dichos cañones a Tungasuca. (La rebelión de Túpac Amaru, 1971, vol. 2, pp. 337-338)

\section{MARCHA AL CUSCO. LA BATALLA FINAL}

Durante el mes de diciembre se suceden las acciones lideradas por Túpac Amaru. El 13 de diciembre, Micaela Bastidas lanzó un edicto nombrando coronel a José Mamani y capitán a Simón Aymi Tupa. Poco después recibió una carta de Marcos de la Torre desde Acomayo, informándole que carecía de armas y soldados, lo que corrobora Tomás Guasa cuando señala: “[...] me hallo solo sin ninguna persona a nuestro favor; yo sé que nos esperan con bastantes soldados en Pilpinto" (La rebelión de Túpac Amaru, 1971, vol. 2, p. 356).

Túpac Amaru llegó el 15 de diciembre a Tungasuca, y de allí partió al Altiplano con la intención de conducir el contingente hacia el Cusco. La situación se tornaba cada vez más difícil; el 22 de diciembre, el general José Antonio de Areche dirigió una carta a la Corte española dándole cuenta del movimiento rebelde. Ante esto, Túpac Amaru 
expidió el "Bando a los arequipeños" con mensajes unitarios y asumió la conducción de la marcha hacia el Cusco.

Túpac Amaru y Micaela Bastidas avanzan juntos hasta llegar el 4 de enero de 1781 a los cerros que rodean la ciudad del Cusco. Pero después de diez días de infructuosos ataques deben replegarse. Túpac Amaru parte a Acomayo y Micaela a Tinta. Durante el asedio a la ciudad enfrentaron la oposición del cacique de Anta, Nicolás de Rosas, y del cacique Mateo Pumacahua ${ }^{1}$, atrincherados en la fortaleza de Sacsayhuamán, ambos aliados de los españoles, como consta en el informe del Cabildo del Cusco de 1783 ( $\mathrm{La}$ rebelión de Túpac Amaru, 1971, vol. 2, p. 118).

En esas semanas, Micaela Bastidas asumió la coordinación del ataque a Puno, comandado por Ramón Ponce, y la ofensiva sobre Arequipa. Por su parte, Túpac Amaru se preparaba para enfrentar a José Antonio de Areche, que avanzaba hacia el Cusco al frente de un ejército de miles de soldados. Con anterioridad, el 3 de enero de 1781, Túpac Amaru había dirigido un oficio al Cabildo del Cusco solicitando su intervención para permitir el ingreso a la ciudad del padre Domingo Castro, de Ildefonso Bejarano y del capitán Bernardo de la Madrid, en calidad de emisarios.

Pero este oficio y otro del 10 de enero no fueron respondidos. No hay tregua ni negociaciones. El 15 de enero, el virrey Francisco de Jáuregui ordena preparar las milicias para sofocar el levantamiento dirigido por "el indio rebelde Josef Gabriel Tupa Amaro". La orden es liquidar la rebelión y a los principales líderes indígenas. El 13 de marzo, Julián Túpac Katari sitió La Paz durante 109 días, y entre el 18 y el 22 de ese mes, Túpac Amaru logró un importante triunfo estratégico en Pucacasa. Pero el ejército español avanza incontenible y se acerca el gran enfrentamiento.

En esos difíciles días, Micaela Bastidas, llamada mamanchic por los indios, que significa "madre de los pobres", multiplica sus tareas y afanes. El 23 de marzo de 1781, le envía la última carta a Túpac Amaru, donde le informa el movimiento de los soldados españoles y que está enviando un cañón a Paruro (La rebelión de Túpac Amaru, 1971, vol. 3, p. 57).

El 6 de abril de 1781, José Antonio de Areche, al frente de una poderosa fuerza de miles de soldados, derrotó a Túpac Amaru en la batalla de Checacupe ${ }^{2}$. Sin embargo, este logró huir y se refugió en Langui, en la casa de un cercano colaborador, Ventura Landaeta, confiado en su fidelidad. Horas más tarde fue entregado a los españoles con Antonio Bastidas; su hijo Mariano y Diego Túpac Amaru lograron escapar (La rebelión

1 Pumacahua, en 1814, se pasó al bando patriota y participó en el levantamiento del Cusco, y en las sublevaciones de Arequipa, Huamanga y La Paz. Fue ejecutado por los españoles.

2 Por su actuación en la derrota de Túpac Amaru se le concedió la orden de Carlos III. 
de Túpac Amaru, 1971, vol. 2, pp. 656-657). Ventura Landaeta, el traidor, obtuvo de los españoles una pensión vitalicia y una cuantiosa recompensa.

Ese día Micaela Bastidas recibió un mensaje secreto anunciándole la detención, y partió con sus hijos y varios familiares por el camino de Livitaca, donde fue emboscada, traicionada también por Ventura Landaeta. El 12 de abril de 1781, fueron apresados Túpac Amaru, Micaela Bastidas, sus hijos Hipólito y Fernando. También Antonio Bastidas, Cecilia Túpac Amaru, Tomasa Tito Condemayta, Úrsula Pereda, Isabel Coya y Francisca Aguirre. Días antes, el 7 de abril había sido detenida Marcela Castro, madre de Diego Túpac Amaru.

\section{JUZGADOS Y EJECUTADOS}

El juicio se inició el 17 de abril de 1781 y culminó tres meses después, el 14 de julio³. Incluyó a más de doscientos prisioneros y se realizó en el antiguo colegio de los jesuitas del Cusco, San Francisco de Borja, convertido en cárcel. Dos escribanos siguieron el proceso: Manuel Espinavete López y José Palacios, cercano a Túpac Amaru, convertido después en "delator a favor de la administración colonial. Más tarde, también él fue investigado y perseguido" (Roedl, 2002).

Cuando Areche intentó que Túpac Amaru, a cambio de favores, delatase a "sus cómplices de la rebelión", este le respondió:

Nosotros dos somos los únicos conspiradores; Vuestra merced por haber agobiado al país con exacciones insoportables y yo por haber querido libertar al pueblo de semejante tiranía. Aquí estoy para que me castiguen solo, al fin de que otros queden con vida. (La rebelión de Túpac Amaru, 1971, vol. 3, p. 881)

El 22 de abril, Micaela Bastidas se enfrentó al juez Mata Linares, que también pretende engañarla para que delate a otros combatientes. Pero ella niega cargos y no se contradice. Incluso protegió a los sacerdotes Antonio López de Sosa e Ildefonso Bejarano, que fueron desterrados y encerrados en el convento de San Francisco de Cádiz. Poco después el visitador Areche dictó sentencia:

Por complicidad en la Rebelión premeditada y ejecutada por Túpac Amaru, auxiliándolo en cuanto ha podido, dando las órdenes más vigorosas y fuertes, para juntar gente, [...] invadiendo las provincias para sujetarlas a su obediencia, condenando al último suplicio al que no obedecía las órdenes suyas o de su marido, [...] esforzando y animando a los indios, dando bastones de Coroneles a los que creía más adictos; hablando con horror de los españoles, y con expresiones que imprimiesen mayor odio a los naturales, [...] dando pases para que sus soldados no impidiesen a los de

3 Los protocolos judiciales están en el Archivo General de las Indias en Sevilla. Fueron publicados con el título Los procesos a Túpac Amaru y sus compañeros, en la serie Colección Documental del Bicentenario de la Revolución Emancipadora de Túpac Amaru (1981 y 1982). 
su facción; escribiendo cartas a fin de publicar los felices sucesos de su marido, [...] pidiendo le enviasen gente, con pena de la vida al inobediente. (La rebelión de Túpac Amaru, 1971, vol. 2, p. 736)

El viernes 18 de mayo de 1781, amaneció nublado y el cielo gris. La Plaza de Armas del Cusco, rodeada de soldados armados con fusiles y bayonetas frente a una muchedumbre silenciosa. Los detenidos salieron esposados, metidos en zurrones y arrastrados a la cola de un caballo. Fueron ahorcados José Verdejo, Andrés Castelo, Antonio Bastidas y Pedro Mendigure ${ }^{4}$ A Francisco Túpac Amaru y a Hipólito Túpac Amaru les cortaron la lengua antes de ahorcarlos. A Tomasa Tito Condemayta se le dio garrote. Micaela Bastidas y Túpac Amaru presenciaron estas ejecuciones y la muerte de su hijo Hipólito.

Según el visitador Areche, la ejecución de Micaela Bastidas debía ir acompañada "con algunas cualidades y circunstancias que causen terror y espanto al público; para que a vista del espectáculo, se contengan los demás, y sirva de ejemplo y escarmiento" (Markham, citado por Bonilla, 1971, p. 175). La ejecución como espectáculo de terror, la "masculinización de su persona percibida en los edictos redactados contra Micaela y en los testimonios legales en torno a su juicio recalcaban la idea de que no merecía ser tratada como una mujer" (Meléndez, 2003, pp. 767-769).

Condeno a Micaela Bastidas a la pena de muerte y la justicia que le mando hacer es que sea sacada de este cuartel, arrastrada con un soga de esparto al cuello, atados pies y manos, con voz de pregonero que publique su delito, siendo llevada en esta forma al lugar del suplicio, donde se halla un tabladillo, en que por su sexo y consultando la decencia, se la sentará y ajustará el garrote, cortándosela allí la lengua, e inmediatamente se la hará morir con horca [...]. Y luego será descuartizado su cuerpo, llevando la cabeza al cerro de Piccho, que será fijada en una picota con una tarjeta en que se leerá su delito; un brazo a Tungasuca, otro a Arequipa, y una de las piernas a Carabaya conduciéndose lo restante del cuerpo al mismo cerro de Piccho, donde será quemado con el de su marido [...]. José Antonio de Areche. Ciudad del Cusco, 16 de mes de mayo de 1781. (La rebelión de Túpac Amaru, 1971, vol. 2, pp. 736-737)

Antes de matarla le cortaron la lengua, y "se le dio garrote, en que padeció infinito; porque teniendo el cuello muy delgado, no podía el torno ahogarla, y fue menester que los verdugos [...] dándole patadas en el estómago y pechos, la acabasen de matar" (La rebelión de Túpac Amaru, 1971, vol. 2, p. 775). A Túpac Amaru le cortaron la lengua y ataron sus brazos y piernas a cuatro caballos. Pero por más que tiraron no pudieron matarlo, hasta que Areche ordenó que le corten la cabeza. Ese viernes a las 12 del día:

se levantó un fuerte refregón de viento, y tras este un aguacero, que hizo que toda la gente, y aun las guardias, se retirasen a toda prisa. Esto ha sido causa de que lo indios se hayan puesto a decir que el cielo y los elementos sintieron la muerte del Inca que

4 También fueron ahorcados Antonio Oblitas, Francisco Torres, Gregorio Enríquez, Pedro Mamani, Isidro Puma, Miguel Mesa, Diego Berdejo, Miguel Anco y José Amaro. 
los españoles inhumanos e impíos estaban matando con tanta crueldad. (Markham, citado por Bonilla, 1971, p. 175)

La sentencia del visitador Areche contra Túpac Amaru y Micaela Bastidas expresó la condena de la cultura andina. Se prohibió la indumentaria de los caciques, el uso de sus instrumentos musicales y, particularmente, el idioma quechua. Es decir, todo aquello que Túpac Amaru simbolizaba.

\section{LA CARAVANA DE LA MUERTE}

Según un documento oficial, después de la ejecución de Túpac Amaru y de Micaela Bastidas, reinaba la tranquilidad en el Virreinato del Perú (Clement, 1981, pp. 325-334). Todas las provincias y sus pueblos gozan de "suavidad con sosiego, comunicación, confraternidad y una total sujeción, con rendimiento a la Corona de España" (La rebelión de Túpac Amaru, 1971, vol. 1, p. 341). Este era el clima de calma y confraternidad.

El 3 de noviembre de 1781 se rindió Miguel Túpac Amaru con siete rebeldes. El 8 de noviembre, los españoles detuvieron a Túpac Catari y a Miguel Bastidas, sobrino de Túpac Amaru (La rebelión de Túpac Amaru, 1971, vol. 3, p. 148). El 15 de noviembre, se dictó sentencia de muerte contra Túpac Catari, esposo de Bartola Sisa, entonces presa en la ciudad de La Paz, el cual fue ejecutado y descuartizado mientras los españoles convencían a Diego Cristóbal Túpac Amaru de firmar el armisticio (La rebelión de Túpac Amaru, 1971, vol. 3, p. 164).

Finalmente, el 11 de diciembre de 1781, Diego Túpac Amaru firmó el tratado de paz con la condición de que los sobrevivientes fueran indultados. El 27 de enero de 1782, entregó sus armas en Sicuani. El 20 de febrero, repicaron las campanas y se iluminaron las calles "por la pacificación de todas las provincias pertenecientes a este Virreinato" (La rebelión de Túpac Amaru, 1971, vol. 3, p. 240).

Sin embargo, a pesar de que Mariano Túpac Amaru se acogió al Bando de Perdón e Indulto el 14 de diciembre de 1782, dos años después, el 1 de abril de 1784, el virrey del Perú, Agustín de Jáuregui, lo condenó a destierro perpetuo. También fue condenado y desterrado su hermano, Fernando Túpac Amaru de 15 años.

En julio de 1783, las mujeres que participaron en la gesta y familiares de los rebeldes fueron condenados a caminar desde el Cusco hasta el Callao a pie. Debían recorrer descalzas cerca de 1400 kilómetros atravesando las ciudades del Cusco, Huamanga, Huancavelica, Huancayo, Cañete, Lima hasta llegar al Callao. El 1 de octubre de 1783, partió la caravana de la muerte, conformada por 75 mujeres y 17 niñas, "con lo que quedó limpia esta ciudad y sus provincias de la mala semilla de esta infame generación [...]" (La rebelión de Túpac Amaru, 1971, vol. 1, p. 145), señala un documento oficial. 
La relación de las mujeres de la caravana de la muerte figura en el Real Convictorio de San Carlos como homenaje al heroico sacrificio de la mujer peruana: Margarita Acevedo, Nicolaza Aguirre, Susana Aguirre, Ventura Aguirre, Rosa Arce, Rosa Barrantes Túpac, Juana Bastidas Arce, Bernarda Bastidas, María Cahuana, Dionisia Cahuaytopia, Antonia Callo, Santusa Canqui, Micaela Castellanos, Antonia Castro, Paula Castro, Mónica Castro, Marcela Castro Puyucahua, Santusa Castro Puyucahua, Antonia Caya, Agustina Cerna, Micaela Colque, Úrsula Colque, Rosa Condorcanqui, Margarita Condorcanqui, María Dominga Condori, Tomasa Condori, María Cruz Huamani, Margarita Cusi, María Cusi Huarcay, Ana María Díaz Castro, Patricia Díaz Castro, Patricia Díaz, Antonia Escobedo, Bartola Escobedo, Isidora Escobedo, Ascencia Flores, María Fuentes, Ascencia Fuentes Castro, Francisca Fuentes Castro, Antonia Gallo, Isabel Gonzales, Catalina Guancachoque, Francisca Herrera, Micaela Incabueno, María Luque, María Llallia, Juliana Mallqui, Georgina Marqui, Mariana Mendigure, Juana Molina, Ventura Monjarras, Ventura Monsacia, Margarita Noguera, Paula Noguera, Rosa Noguera, Pascuala Olmos, Úrsula Pereda, Narcisa Puyucahua, María Ramos, Sebastiana Ramos, Rosa Roca, Antonia Tito Condori, Felicia Tito Condori, Manuela Tito Condori, Francisca Toledo, Melchora Toledo, Francisca Torres, Margarita Torres, Nicolaza Torres, Antonia Túpac Amaru, Manuela Túpac Amaru, Paula Túpac Amaru, Rosa Túpac Amaru, Tomasa Sisa, Andrea Uscamayta, Simona Venero, Rosa Vilca. Además de 17 menores de edad.

Solo 15 mujeres llegaron a la fortaleza del Real Felipe a fines de diciembre de 1783. En otro barco que transportaba a los desterrados a España, murieron en el puerto de Río de Janeiro, entre abril y mayo de 1784, Susana Aguirre, esposa de Juan Bautista Túpac Amaru, Nicolaza Torres, Andrea Uscamayta y Antonia Castro. Sobrevivieron Fernando Túpac Amaru y Juan Bautista Túpac Amaru.

\section{FERNANDO TÚPAC AMARU}

Fernando Túpac Amaru tenía 11 años cuando presenció la ejecución de sus padres José Gabriel y Micaela, y de su hermano Hipólito. Fue condenado al destierro y permaneció en una celda del Callao hasta que, en 1784, partió en un navío con destino a Cádiz. Pero el barco naufragó en la costa de Peniche, Portugal.

Un oficial lo salvó y así pudo llegar a Cádiz. A pesar de contar solo con 15 años, fue encarcelado en las mazmorras del castillo de San Sebastián y después en Santa Catalina. Por intermedio de un sacerdote, le escribió una carta al rey Carlos III solicitando su liberación. Poco después, fue trasladado a Madrid, donde pudo estudiar en las Escuelas Pías de Lavapiés y Getafe. Período de su vida muy difícil porque no pudo conseguir trabajo, como consta en una carta del 29 de julio de 1792, en la que "solicita 
que se le destine algún trabajo. Le asignaron nueve mil reales anuales, dinero que nunca llegó" (La rebelión de Túpac Amaru, 1971, vol. 3, pp. 493, 495, 497-499, 501). La pérdida de sus padres, de sus hermanos, el dolor de los años de confinamiento, la lejanía de su país, de su cultura, se manifestaron en una permanente depresión y melancolía. Murió en Madrid el 19 de agosto de 1799. Tenía 31 años.

\section{JUAN BAUTISTA TÚPAC AMARU}

Juan Bautista Túpac Amaru nació en Tungasuca en 1747 y participó en la insurrección de su medio hermano José Gabriel Túpac Amaru. Se casó con Susana Aguirre, que murió durante el viaje de destierro a España. Areche lo condenó a recibir doscientos azotes en las calles del Cusco y lo sentenció a seis años de prisión. Pero el coronel Gabriel Avilés y del Fierro, virrey del Perú en 1801, lo dejó en libertad. Sobrevivió sin ningún recurso, pues todos sus bienes habían sido embargados y saqueados. Posteriormente, lo detuvieron y lo condenaron a diez años de destierro.

Partió en el navío El Peruano el 13 abril de 1784, con Mariano Túpac Amaru y 60 personas más (La rebelión de Túpac Amaru, 1971, vol. 3, pp. 886-887). La mayoría murió de escorbuto antes de llegar a Río de Janeiro, donde permanecieron cuatro meses. En Cádiz, estuvo preso tres años y tres meses en el castillo de San Sebastián. "No recuerdo - escribe - un solo rasgo humano de los españoles que se sucedieron a custodiarme" (La rebelión de Túpac Amaru, 1971, vol. 3, p. 889). De allí fue conducido a la isla de León, Sancti Petri, y a Ceuta, donde llegó el 1 de junio de 1788. Entonces entabló amistad con el agustino Marcos Durán Martel, la única persona que lo apoyó en su esperanza de regresar al Perú.

En 1820, en pleno proceso de independencia del Perú, las Cortes decretaron que todos los americanos presos por opiniones políticas fuesen puestos en libertad y conducidos a sus países. Tras permanecer 32 años en Ceuta, Juan Bautista Túpac Amaru solicitó la libertad, que le fue negada por el auditor Antonio García, con el pretexto de que estaba bajo la jurisdicción del Consejo de Indias. Entonces viajó con Marcos Durán Martel a Algeciras para tramitar su libertad, que finalmente logró, y el 3 de julio de 1822 se embarcaron con destino a América del Sur.

Llegó el 12 de octubre de 1822 a Buenos Aires, donde fue recibido con afecto y amistad por los patriotas que habían luchado por la independencia. El gobierno le otorgó una pensión de 30 pesos mensuales y le solicitó que escribiera sus memorias, mediante decreto firmado por Bernardino Rivadavia, que en 1826 accedería a la presidencia de Argentina. Al inicio de su testimonio Dilatado cautiverio, bajo el gobierno español, de Juan Bautista Tupamaru, 5. ${ }^{\circ}$ nieto del último emperador del Perú, escribe: 


\begin{abstract}
A los 80 años de edad, y después de 40 de prisión por la causa de la independencia, me hallo trasportado de los abismos de la servidumbre á la atmósfera de la libertad, y por un nuevo aliento que me inspira, animado á mostrarme á esta generación, como una víctima del despotismo que ha sobrevivido á sus golpes, para asombro de la humanidad, y para poderle revelar el secreto de mi existencia como un exquisito y feroz artificio que se transmitían los tiranos para tener el placer de amargarla. Tres reyes españoles se han complacido igualmente en verme arrastrar una existencia degradada y humilde; ya se había perdido la tradición del motivo de mis cadenas, y hasta las instituciones casi todas se hallaban alteradas por la acción del tiempo y la distinta sucesión de monarcas, y solo yo era conservado sin libertad para su recreo ${ }^{5}$.
\end{abstract}

El 15 de mayo de 1825, Juan Bautista Túpac Amaru le escribió una carta a Simón Bolívar solicitando su apoyo para viajar al Perú (La rebelión de Túpac Amaru, 1971, vol. 3, p. 908), ese anhelo que le había permitido resistir el odio y la crueldad. Falleció en Buenos Aires el 2 septiembre de 1827, sabiendo que a pesar de todo la independencia del Perú se había logrado el 28 de julio de 1821. Con su muerte, concluye la gesta de Túpac Amaru y Micaela Bastidas.

\title{
REFERENCIAS
}

Antologíadela Independenciadel Perú.(1972). Lima:Comisión Nacional delSesquicentenario de la Independencia del Perú.

Bonilla, J. (1971). La revolución de Túpac Amaru. Lima: Ediciones Nuevo Mundo.

Clement, J. P. (1981). La opinión de la Corona española sobre la rebelión de Túpac Amaru. Acta Literaria Academiae Scientiarum Hungaricae, 23(3-4), 325-334.

La rebelión de Túpac Amaru (vols. 2, 3 y 4). (1971). Lima: Comisión Nacional del Sesquicentenario de la Independencia del Perú, Colección Documental de la Independencia del Perú (CDIP).

Loayza, F. (1945). Mártires y heroínas. Lima: Los Pequeños Grandes Libros de Historia Americana.

Meléndez, M. (2003). La ejecución como espectáculo público: Micaela Bastidas y la insurrección de Túpac Amaru, 1780-81. En C. Ruiz Barrionuevo (Coord.), La literatura iberoamericana en el 2000. Balances, perspectivas y prospectivas. Salamanca: Universidad de Salamanca.

O'phelan, S. (1995). La gran rebelión de los Andes. De Túpac Amaru a Túpac Catari. Lima: Centro de Estudios Regionales Andinos Bartolomé de Las Casas; Petroperú.

5 Un ejemplar está en la Biblioteca Nacional de Buenos Aires. En 1941, el libro fue publicado con el título de Cuarenta años de cautiverio por Francisco A. Loayza y, en 1971, en La rebelión de Túpac Amaru (vol. 3). 
LIENZO 41 / HISTORIA \& PEDAGOGÍA

Roedl, B. (2002). Causa Tupa Amaro. El proceso a los tupamaros en Cuzco, abril-julio de 1781. Revista Andina, 34, 99-121.

Túpac Amaru, J. B. (1942). Las memorias de Túpac Amaru. Cuarenta años de cautiverio (prólogo de C. Romero y notas de F. Loayza; 2. ${ }^{a}$ ed.). Lima: Los Pequeños Grandes Libros de la Historia Americana. 